\title{
Mild cerebrospinal fluid pleocytosis in a Parkinson's disease patient with deep brain stimulation
}

\section{Emilyrose Havrilla, Marcie Rabin, Edward Zampella, Roger Kurlan*}

Atlantic Neuroscience Institute, Overlook Medical Center, Summit, NJ, USA;

*Corresponding Author: roger.kurlan@atlantichealth.org

Received 15 November 2013; revised 17 December 2013; accepted 25 January 2014

Copyright (C) 2014 Emilyrose Havrilla et al. This is an open access article distributed under the Creative Commons Attribution License, which permits unrestricted use, distribution, and reproduction in any medium, provided the original work is properly cited. In accordance of the Creative Commons Attribution License all Copyrights (C) 2014 are reserved for SCIRP and the owner of the intellectual property Emilyrose Havrilla et al. All Copyright (C) 2014 are guarded by law and by SCIRP as a guardian.

\section{INTRODUCTION}

Deep brain stimulation surgery (DBS) involves the stereotactic placement of electrodes in specific brain regions followed by electrical stimulation using an implanted stimulator. This has become a standard treatment approach for patients with Parkinson's disease (PD) and dystonia and is being studied for a variety of other conditions. We now report on a PD patient with DBS who underwent lumbar puncture as part of an evaluation for delirium. A mild pleocytosis in the cerebrospinal fluid (CSF) was found which, given the apparent absence of infection, may have been induced by the DBS. This is the first published report of a CSF study in a patient with DBS.

\section{CASE REPORT}

At age 36, this man presented with a resting tremor of the left arm and was diagnosed as having Parkinson's disease (PD). He was treated with levodopa and dopamine agonists but experienced progression of the illness. At the age of 54, the patient underwent bilateral subthalamic nucleus DBS which produced excellent results. The patient remained stable for several years except for the development of mild dementia, treated with donepezil $10 \mathrm{mg}$ daily. At age 62 he was hospitalized due to fever, cough and delirium with visual hallucinations, delusions and confusion. His features of PD had worsened. There was no warmth, redness or swelling around his DBS stimulator or wires. He was found to have elevated peripheral white blood count $(18,530$ cells/nL) and a chest X-ray revealed a left lower lobe infiltrate. He was treated with ceftriaxone at 2 grams, 2 times daily, and his amantadine dosage was reduced from $100 \mathrm{mg}$ twice daily to $100 \mathrm{mg}$ each morning to reduce any possible contribution to delirium. Blood and sputum cultures were nega- tive. A lumbar puncture revealed clear, colorless cerebrospinal fluid with normal opening pressure, glucose level of $81 \mathrm{mg} / \mathrm{dl}$ and total protein of $66 \mathrm{mg} / \mathrm{dl}$. There were 12 white blood cells (WBC) $/ \mathrm{mm}^{3}, 68 \%$ of which were polymorphonuclear, and with no red blood cells. CSF gram stain revealed no organisms and bacterial and viral cultures showed no growth. Immunological tests for herpes simplex, Eastern equine, and West Nile viruses were negative. Following the 10 day course of antibiotic therapy and over the next 3 weeks the patient's cognition and motor function returned to near baseline levels. While in a rehabilitation facility he did experience some ongoing confusion.

\section{DISCUSSION}

There have been no prior reports of CSF analysis in a patient with DBS. Our patient with PD and DBS was found to have a mild CSF polymorphonuclear pleocytosis of $12 \mathrm{WBC} / \mathrm{mm}^{3}$. Normally CSF contains fewer than $5 \mathrm{WBC} / \mathrm{mm}^{3}$ and there should be no polymorphonuclear leukocytes. It is unlikely that the findings in our patient's CSF reflect a central nervous system infection given the fairly quick recovery and the normal CSF glucose, protein, stains, cultures and immunological results, although we can't fully exclude this possibility. The delirium and motor decline most likely were caused by the superimposed pneumonia. The blood leukocytosis supports this being a clinically meaningful infection. It is common for PD or dementia patients to develop delirium or transient clinical decline in the setting of fever and an intercurrent infection. We suspect that the mild CSF pleocytosis was caused by the presence of DBS electrodes and wires, which acted as foreign bodies to induce a mild inflammatory response in the brain. Alternatively, the chronic electrical stimulation of the brain may have induced some inflammation. We were unable to identify any oth- 
er reports of the CSF composition in patients with DBS or in patients with other implanted medical devices such as ventricular shunts, in the absence of infection. This case suggests that DBS itself may induce a mild CSF pleocytosis and this finding might mimic a central nervous system infection. The study of more DBS patients is needed to confirm this possibility. 